\title{
Dilemas dos sistemas híbridos de comunicação institucional: análise das tensões e dos conflitos no projeto da Câmara dos Deputados
}

Dilemmas of the hybrid institutional communication systems: analysis of the tensions and conflicts in the media project of the Brazilian House of Representatives

Los dilemas de los sistemas híbridos de comunicación institucional: análisis de las tensiones y de los conflictos en el proyecto de la Cámara de Diputados de Brasil

Antonio Teixeira de Barros

- Pós-doutor em Comunicação pela Universidade Fernando Pessoa, Portugal

- Doutor em Sociologia e mestre em Comunicação pela Universidade de Brasília (UnB)

- Graduação em Comunicação Social - Jornalismo pela Universidade Federal do Piauí (UFPI)

- Docente e pesquisador do Programa de Mestrado em Ciência Política do Centro de Formação da Câmara dos Deputados, vinculado à linha de pesquisa Política Institucional do Poder Legislativo.

- Coordenador do grupo de pesquisa "Interatividade, visibilidade e transparência: estratégias da Câmara dos Deputados para aperfeiçoamento da democracia".

- Co-organizador de obras como: Olhares sobre o parlamento: incursões acadêmicas no território político e Métodos e técnicas de pesquisa de comunicação; organizador de Ciência para comunicação; comunicação para ciência

E-mail:antoniobarros@gmail.com

Cristiane Brum Bernardes

- Doutora em Ciência Política pelo Instituto de Estudos Sociais e Políticos da Universidade do Estado do Rio de Janeiro (IESP-Uerj)

- Mestra em Comunicação e Informação pela Universidade Federal do Rio Grande do Sul (UFRGS)

- Graduada em Comunicação Social - Jornalismo pela UFRGS

- Docente do Mestrado Profissional em Poder Legislativo da Câmara dos Deputados

- Pesquisadora visitante no Centro de Estudos Legislativos da Escola de Política, Filosofia e Estudos Internacionais da Universidade de Hull, no Reino Unido

- E-mail: cris.brum@gmail.com 


\section{Resumo}

Este artigo analisa as tensões típicas de um sistema híbrido de comunicação institucional, a partir de um balanço recente sobre o sistema de comunicação da Câmara dos Deputados. A tendência da comunicação institucional contemporânea é a constituição de sistemas híbridos e integrados, com equipes de diferentes áreas profissionais, como jornalismo, relações públicas, publicidade e mídias digitais. Tal sistema favorece o potencial de agregação de talentos e de possibilidades de divulgação para a sociedade. Por outro lado, também podem surgir tensões e conflitos, em diferentes níveis, principalmente entre as diversas culturas profissionais envolvidas e entre a esfera da gestão e da execução das atividades. 0 estudo destaca os conflitos entre as diferentes culturas profissionais, além das dissonâncias entre o projeto institucional e os interesses dos parlamentares e dos partidos políticos. Conclui que a eficácia institucional do projeto depende de um arranjo político para atenuar essas tensões e conflitos.

PALAVRAS-CHAVE: COMUNICAÇÃO INSTITUCIONAL •COMUNICAÇÃO E POLÍTICA • COMUNICAÇÃO PÚBLICA • CÂMARA DOS DEPUTADOS • MÍDIAS LEGISLATIVAS.

\section{Abstract}

This paper analyzes the typical tensions of a hybrid system of institutional communication, using a recent assessment of the communication system of the Brazilian House of Representatives. The trend of contemporary institutional communication is the creation of hybrid and integrated systems, with teams from different professional fields such as journalism, public relations, advertising and digital media. This system favors the potential aggregation of talent and the possibilities of divulgement to the society. On the other hand it can also give rise to tensions and conflicts at different levels, especially between the different professional cultures involved and between the sphere of management and of conduction of the activities. The study highlights the conflicts between different professional cultures, in addition to the dissonance between the institutional design and the interests of the members of the parliament and of the political parties. It concludes that the institutional effectiveness of the project depends on a political arrangement to ease the tensions and conflicts.

KEYWORDS: INSTITUTIONAL COMMUNICATION • COMMUNICATION AND POLITICS • PUBLIC COMMUNICATION • HOUSE OF REPRESENTATIVES • LEGISLATIVE MEDIA.

\section{Resumen}

El artículo analiza las tensiones típicas de un sistema híbrido de comunicación institucional, a partir de una evaluación reciente del sistema de comunicación de la Cámara de Diputados brasilera. La tendencia de la comunicación institucional contemporánea es la creación de sistemas híbridos e integrados, con equipos de diferentes ámbitos profesionales, como el periodismo, las relaciones públicas, la publicidad y los medios digitales. Este sistema favorece el potencial de agregación de talentos y de posibilidades de difusión para la sociedad. Por otra parte, también pueden surgir tensiones y conflictos, en diferentes niveles, especialmente entre las diversas culturas profesionales participantes y entre la esfera de gestión y ejecución de las actividades. El estudio pone de relieve los conflictos entre las diferentes culturas profesionales, además de las disonancias entre el proyecto institucional y los intereses de los parlamentarios y de los partidos políticos. Se concluye que la eficacia institucional del proyecto depende de un acuerdo político para aliviar las tensiones y conflictos. 
tendência da comunicação institucional contemporânea, com os novos fluxos tecnológicos, éa constituição de sistemas
híbridos e integrados, o que implica a atuação de equipes de diferentes áreas profissionais: jornalismo, relações públicas,
publicidade e mídias digitais. Tal sistema favorece o potencial de agregação de talentos e de possibilidades de divulgação para a sociedade e de interação e relacionamento com os diferentes segmentos de públicos. Por outro lado, também podem surgir tensões e conflitos, em diferentes níveis, principalmente entre as diversas culturas profissionais envolvidas; e entre a esfera da gestão e da execução das atividades.

No caso da comunicação institucional em contextos políticos, essas tensões e esses conflitos podem ser ainda mais ampliados, a exemplo da Câmara dos Deputados, cujo projeto de comunicação institucional é objeto de análise deste artigo, com base nos pressupostos acima destacados. 0 estudo é realizado a partir de um balanço recente da experiência da Câmara dos Deputados, instituição que investiu intensamente em um projeto de comunicação institucional híbrido e complexo nas últimas décadas. 0 texto destaca os conflitos entre as culturas profissionais (jornalistas, relações públicas e publicitários) e as dissonâncias entre o projeto institucional e os interesses dos deputados e partidos.

A metodologia consiste na combinação de duas técnicas de pesquisa. A primeira teve como eixo a análise documental para 0 exame dos textos oficiais que estabelecem as diretrizes e os objetivos institucionais do projeto de comunicação da Câmara. A segunda contou com o suporte de entrevistas em profundidade com 43 profissionais do setor. Trata-se, portanto, de um estudo baseado em dados primários, o qual fazia parte de dois projetos mais amplos'. Os dados apresentados, aqui, portanto, não refletem a totalidade das informações coletadas. Para a elaboração do artigo foi realizado um recorte com o foco já delineado.

\section{O SISTEMA DE COMUNICAÇÃO INSTITUCIONAL DA CÂMARA DOS DEPUTADOS}

A implantação do sistema de comunicação da Câmara começou em 1961, antes mesmo da Ditadura Militar. Naquele ano, foi instalado o Serviço de Radiodifusão e o primeiro produto criado foi o noticiário de vinte minutos para o programa oficial $A$ Voz do Brasil, em 1963. Até a década de 1990, a coordenação dos trabalhos era feita pela Assessoria de Divulgação Institucional e Relações Públicas (Adirp), órgão criado pela Resolução no 20, de 1971. Cabia à Adirp "informar e esclarecer a opinião pública a respeito das atividades da Câmara dos Deputados, utilizando, para isso, os veículos de divulgação e as técnicas de relações públicas, e assessorar o presidente em questões de cerimonial" (Brasil, 1971). O Serviço de Divulgação era responsável por esclarecer a opinião pública "através da imprensa, rádio, televisão e cinema e do sistema próprio de radiodifusão". Percebese, no documento, a referência ao programa $A$ Voz do Brasil, única forma de radiodifusão do Poder Legislativo na época. A Adirp refletia o conceito de comunicação estatal criado pelo antigo Departamento de Imprensa e Propaganda (DIP), que consistia na divulgação das atividades oficiais. Essa intenção teve reflexos na definição das funções e atribuições da Adirp.

O Serviço de Divulgação da Adirp contava com três seções: (1) de Imprensa, responsável pela distribuição de material informativo aos jornais; (2) de Rádio, que fazia a Voz do Brasil e distribuía noticiários para rádios; e (3) de Televisão e Cinema. A esta última competia "elaborar gravações em videoteipe dos debates de Plenário e Comissões; entrevistas ou pronunciamentos a serem distribuídos às emissoras de televisão", entre outras tarefas correlatas. Depois de reformulações e adaptações durante a redemocratização e a partir do trabalho de comunicação da Assembleia Constituinte, o sistema foi reestruturado e a Adirp foi transformada na Secretaria de Comunicação em 1998. A Assembleia Nacional Constituinte, depois de mais de vinte anos de ação legislativa sob a ditadura militar, deu impulso às necessidades de comunicação do Congresso

1 Trata-se do projeto de pesquisa "Comunicação pública no Legislativo", coordenado pelos dois autores. 
Nacional e de abertura para a sociedade. Tal impulso resultou na criação das emissoras de radiodifusão legislativas, a partir da aprovação da Lei do Cabo (Lei 8977/95).

A Secretaria de Comunicação (Secom) da Câmara dos Deputados compreende a comunicação pública como um fluxo contínuo e recíproco de informações entre a instituição e o cidadão, "em sintonia com a transparência e o caráter democrático da instituição Câmara dos Deputados" e é pública "porque assume a responsabilidade de emitir, transmitir e receber mensagens da sociedade brasileira, sempre com o sentido de responsabilidade social" (Malavazi, 2004, p. 26). Além dos veículos de comunicação, a Secom mantém uma série de ferramentas para divulgação institucional, tais como as páginas informativas no Portal da Câmara, as visitas guiadas ou as atividades de relações públicas. Atualmente, a Secom dispõe de sete áreas estratégicas. Quatro delas são os veículos Agência Câmara de Notícias, Jornal da Câmara dos Deputados, Rádio Câmara dos Deputados, TV Câmara. As outras três são: Divulgação Institucional, Relações Públicas e Assessoria de Imprensa.

A Divulgação Institucional coordena ações suplementares de formação de imagem (internet, fotografia e demais mídias alternativas) e supervisiona a produção de clippings e releases. Já a área de Relações Públicas é responsável pela comunicação interna e pela Central de Relacionamento com o Cidadão (Disque-Câmara e Fale Conosco). Também ficam sob a responsabilidade do setor de Relações Públicas: Cerimonial; Eventos; Recepção Oficial; Visitação Institucional e Turismo Cívico, além do portal infantil Plenarinho (www.plenarinho.gov.br).

\section{DISPUTAS INTERNAS}

As tensões entre a cultura profissional das diferentes áreas, tais como jornalismo, relações públicas, publicidade, rádio e tevê (Blumler; Gurevitch, 1986), são constantes no sistema de comunicação da Câmara dos Deputados. Enquanto os jornalistas enxergam o Parlamento, primordialmente, como uma fonte privilegiada de informações, os demais profissionais de comunicação pensam em termos de gestão de crise ${ }^{2}$, relacionamento com mídia e gestão da reputação institucional. De certa forma, a diversidade de visões também transparece nas diferenças captadas entre as atividades de relações públicas - destinadas a preservar a imagem da instituição e realizar sua comunicação com seus diferentes públicos - e de jornalismo - interessado em veicular informações úteis sobre a instituição para a população. Resumindo, enquanto os servidores de relações públicas e dos setores administrativos acham que os veículos legislativos devem oferecer subsídios para a gestão institucional da imagem da Câmara dos Deputados - opinião compartilhada pelos deputados -, os jornalistas acham que as mídias legislativas devem levar informações relevantes sobre a Câmara para a população brasileira, o que inclui informações negativas para a própria imagem da instituição ou para seus integrantes.

É importante ressaltar, no entanto, que o principal problema diz respeito à atividade dos veículos de comunicação, pois os próprios jornalistas sabem e concordam com a realização de atividades de comunicação institucional pela própria Secom. 0 que muitos deles parecem defender, contudo, é que essas atividades sejam separadas da prática e dos produtos jornalísticos. Ou seja, a comunicação das iniciativas dos demais órgãos da Câmara, quando não houver interesse do público desses veículos sobre elas, deve ser feita pela Assessoria de Imprensa da Casa, não pelos repórteres e editores da Agência Câmara ou da TV Câmara.

Em princípio, essa separação entre as áreas jornalística e de relações públicas na Secom parece racional, mas não é o que ocorre na prática. Um exemplo bastante comum são as exposições realizadas nas dependências da Câmara. Eventos

2 No Parlamento, as crises de imagem são constantes. Nesse sentido, não estamos tratando de nenhuma em específico, mas em termos gerais. 
desse tipo têm, claramente, uma intenção de promover a imagem da instituição e fazer com que mais pessoas circulem pelo Parlamento, visitem os prédios do Legislativo e obtenham mais informações sobre a instituição. Mas os veículos de comunicação do Parlamento não deveriam divulgar informações sobre eles, por conta desse caráter institucional? Interessa ao público da Rádio Câmara, por exemplo, saber que os quadros desse ou daquele pintor estão expostos no Prédio Principal?

A questão subjacente é que a divisão entre informação puramente institucional e informação de interesse público não é tão bem delimitada quanto supõem muitos estudiosos de comunicação e de política (Bernardes, 2010; Blumler e Gurevitch, 1986; Queiroz, 2007). Informações que sirvam para promover a imagem de uma instituição podem, sim, ser fundamentais para os diferentes públicos daquela organização e, ao mesmo tempo, cumprir funções públicas importantes. 0 problema é transformar o caráter público da comunicação institucional em comunicação laudatória ao Poder Legislativo, porque mesmo a informação institucional precisa levar em conta o interesse público de uma instituição como o Parlamento.

Sob a perspectiva institucional, as mídias legislativas são veículos governamentais ou estatais, isto é, controlados por instâncias de governo e com objetivos declaradamente políticos. Entretanto, os produtores têm algumas restrições ao conceito, exatamente porque, como jornalistas, não querem que sua atividade seja identificada como comunicação política, ainda que admitam a existência desse fator no seu trabalho. Um deles relembra, em depoimento:

Comunicação estatal, como eu já disse, vem da época do conceito do estado não-democrático, ou dominado pelo poder econômico ou dominado por forças políticas autoritárias que não se baseavam em eleições democráticas. Então, comunicação estatal é um conceito diferente da comunicação pública. A comunicação pública deve ter a participação do estado, provavelmente, porque é através do estado que se viabiliza a distribuição dos recursos de uma sociedade, os impostos que você e eu pagamos, eles vão para um caixa único do tesouro federal, estadual ou municipal, e cabe ao estado redistribuir esses recursos para atividades de interesse da sociedade. Então, nesse sentido, a comunicação pública tem que contar, realmente, com recursos públicos. Mas não exclusivamente. Nada impede que outras instituições, como, no caso, as universidades americanas são um exemplo disso, recebem também dinheiro de empresas, contribuições de entidades privadas, assim como recebem fundos estatais. Acho que esse seria um bom conceito para a comunicação pública se viabilizar num país como o Brasil.

De acordo com o depoimento, o conceito de comunicação estatal ficou associado de forma pejorativa ao estado autoritário e, por isso, os produtores evitam usar o termo, ainda que ele possa definir com razoável exatidão a comunicação exercida pelas mídias legislativas, afinal, controladas por um poder estatal.

Para outros profissionais, contudo, o conceito de estatal não poderia ser aplicado ao Parlamento, pois o embate interno ao Poder Legislativo não reflete, como no Executivo, as forças partidárias que controlam o estado e que fariam a verdadeira comunicação estatal, portanto.

E as tevês legislativas são as tevês que maior espaço dão à oposição. Em nenhuma tevê, em nenhum veículo os partidos de oposição têm tanto espaço, tanta exposição quanto nas tevês legislativas. Eu acho que isso combate um pouco a ideia de que é uma tevê estatal. Porque, veja o seguinte: o estado é controlado por um governo, e o governo é feito por um partido, e nem por isso o partido do governo é o que detém maior espaço na nossa tevê. Então é meio que um contrassenso dizer estatal. Estatal como? o que é do estado reflete o grupo de poder que controla o estado, o que está no poder naquele momento. Não é o caso da nossa tevê, dos nossos veículos em geral. Ou então a gente é extremamente desenvolvido politicamente e não percebeu ainda.

Nessa perspectiva, é de ressaltar a confusão entre governamental - que diz respeito ao partido ou força política que chegou ao poder, de caráter transitório - e estatal, referente ao que é público, de todos os participantes da sociedade, com um caráter

3 Todos os depoimentos citados neste artigo, grafados em itálico, foram concedidos à pesquisadora Cristiane Brum Bernardes, entre 2008 e 2009 , por profissionais que atuam nas mídias legislativas e na Secom da Câmara dos Deputados. 
mais permanente. Interessante também é o fato de que, ao mesmo tempo em que rejeita o rótulo de "estatal-governamental", o profissional afirma que o personalismo nas relações políticas no Congresso dificulta o uso "republicano" dos veículos.

0 fato de você ter uma política muito personalista, você ter uma fragilidade partidária, o nosso Congresso é muito mais ditado pelas pessoas do que pelos partidos, acho que o Congresso é forte como instituição, mas por trás dele tem pessoas, não tem partidos, não tem instituições políticas, o Congresso em si é a instituição, então isso torna esses meios muito sujeitos a manipulação, sujeitos a uso político, com finalidade pouco republicana, digamos assim.

Emcerta medida, o jornalista chama a atenção para uma visão comum do estado brasileiro, identificada nas análises de muitos pesquisadores e também por vários atores sociais como "personalista". 0 estado brasileiro seria pouco "burocratizado", no sentido de Weber, porque pouco racional, sem as características que o autor alemão atribui ao estado racional-legal: impessoalidade, eficiência, rotinização do trabalho, rigidez das regras. Segundo essa visão, as normas legais são mais fluidas no Brasil, dependem dos atores envolvidos nos processos, ou seja, não são as mesmas para todos.

A confusão entre relações públicas e jornalismo, por seu turno, parece estar sendo superada aos poucos e as atividades acabam conquistando seus próprios espaços na estrutura, mais de dez anos depois da criação das emissoras legislativas. Segundo um diretor, em entrevista durante a realização desta pesquisa", a Secom "nasceu para ser uma assessoria de apoio à presidência da Câmara, tanto que é ligada ao presidente". Somente em 2003 o assessor de imprensa do presidente da Câmara deixou de acumular o cargo de Secretário de Comunicação, provavelmente, por causa da complexidade que assumiu a tarefa de gerenciar uma estrutura crescente de comunicação. Na mesma época, foi criado o cargo de assessor de imprensa da Câmara, exercido por servidor de carreira, ao contrário dos assessores da presidência, geralmente funcionários indicados politicamente.

Como ressalta o gestor anteriormente citado, houve uma profissionalização da comunicação na Câmara, com a separação entre Secom, assessoria de imprensa do presidente e assessoria de imprensa da Casa. "Hoje você tem uma estrutura em que o secretário de Comunicação, obviamente, despacha diretamente com o presidente, participa de todas as conversas com o presidente, mas ele não responde pelo presidente, ele não responde pelo dia a dia do presidente" ${ }^{\text {, }}$, conclui o gestor.

\section{Organização burocrática institucional}

Diferentes atividades que precisam alcançar diferentes públicos internos e externos e uma estrutura dual, composta por profissionais de relações públicas, jornalistas, publicitários e dasáreas de rádio, TV emídias digitais, entre outras especialidades, dificultam a gestão da Secom. Aliadas às contradições internas, estão dificuldades na convivência de profissionais treinados no mercado com a estrutura burocrática do serviço público. A burocracia e os entraves administrativos para realização de tarefas cotidianas da comunicação institucional são citados por várias entrevistados como as principais dificuldades encontradas no trabalho. Por exemplo, o sentimento do "funcionalismo público" e seu ritmo considerado lento e pouco profissional, em contraste com a identidade dos profissionais de comunicação, acelerada e imediatista, parece desagradar os profissionais, especialmente aqueles que já trabalharam na iniciativa privada. Como mostram os depoimentos coletados durante a pesquisa:

Há momentos em que você realmente esbarra em uma estrutura de burocracia interna, de você não fazer tudo no ritmo que você gostaria de fazer. O ritmo que a gente tem que seguir acaba sendo o ritmo da Casa. Então, se você precisa de um equipamento, se você tem uma proposta de cobertura fora, a gente tem que fazer com muita antecedência, porque tem todo um trâmite, um processo. Isso às vezes dificulta.

4 Entrevista concedida a Cristiane Brum Bernardes, em dezembro de 2009.

5 Idem. 
A questão não parece ser apenas a existência de regras rígidas para realização das atividades no serviço público, mas uma outra lógica que rege as relações profissionais dentro de umórgão público atravessado por tensões políticas. Como executores de uma atividade-meio, isto é, um trabalho que é necessário para que outros atores possam cumprir suas tarefas dentro da instituição, os profissionais da Secom precisam manter uma relação estreita com todos os demais setores e integrantes do Parlamento: assessores, servidores, deputados. Afinal, como afirmam estudiosos da comunicação organizacional, a integração de uma instituição só ocorre por meio do processo comunicacional (Torquato, 1986, p. 16).

Cabe destacar a dinâmica do jornalismo como "forma imanente de controle e distribuição de poder material e simbólico" (Gomes, 2004, p. 53), ou seja, uma atividade que se caracteriza como "um sistema de conflito na busca, controle e distribuição de capital simbólico". Essa perspectiva está alinhada à sociologia de Bourdieu e seu conceito de campo social. Conforme ressalta Gomes (2004, p. 54), a autoridade jornalística é adquirida pela acumulação de capital jornalístico, dando ao seu portador a competência jornalística, que consiste na autorização para falar e agir com autoridade. Equivalente da credibilidade, a autoridade jornalística permite ao detentor o poder sobre a própria estrutura e os mecanismos constitutivos da atividade, ou seja, o poder de definir as regras do jogo.

No caso das mídias legislativas, a autoridade jornalística dos profissionais é constantemente desafiada pelos demais atores sociais que participam da instituição. Esses atores, entre os quais estão os deputados, os profissionais de relações públicas, assessores políticos e de comunicação, além dos servidores dos demais órgãos da Câmara, tentam interferir no processo de definição de regras de noticiabilidade e modificar os procedimentos jornalísticos. Há uma disputa constante da Secom, portanto, não apenas com o parlamentar - que exerce o papel duplo de "patrão" e fonte de informação -, mas também com os próprios colegas de outros setores da Câmara para definição do que merece e do que não merece ser divulgado sobre a instituição. Como afirma um profissional, é uma relação "muito complexa".

A complexidade dessa relação deriva, em parte, do fato de que a comunicação da Câmara tem um forte viés institucional, também chamada por vários autores de organizacional. Por tratar-se o Parlamento de uma instituição política, preferimos o primeiro termo. Efetivamente, como veículos de comunicação mantidos por uma instituição política e governamental, as mídias da Câmara realizam um trabalho de gestão de imagem e exibem uma série de conteúdos informativos destinados a comunicar valores, serviços e direitos dos cidadãos. Nesse sentido, ao efetuarem a comunicação da Casa com o público brasileiro, tais mídias funcionam como veículos institucionais.

Apesar do alto teor informativo, grande parte do que é produzido pelos veículos da Câmara não pode ser considerado jornalismo. Programas de televisão, campanhas informativas de rádio, informações prestadas pela Agência Câmara, entre outros produtos, constituem conteúdos institucionais úteis para a população, mas que não atendem aos critérios de enquadramento jornalístico. Mesmo no caso em que são produzidos por jornalistas, como as campanhas informativas ou os textos sobre projetos de lei, tais produções não são classificáveis entre os gêneros jornalísticos. Em muitos casos, trata-se de produções híbridas, isto é, produtos de alto teor institucional, mas que também exibem um valor informativo de utilidade pública. Aliás, a tendência é verificada em vários tipos de informação, com especial ênfase para a informação política. 
As opiniões colhidas entre os profissionais revelam que existem mais complexidades em jogo no discurso dos profissionais da Secom sobre a própria atividade do que parece reconhecermos à primeira vista. Como afirmam outros jornalistas da TV Câmara, nos dois depoimentos seguintes:

\begin{abstract}
Não vejo a TV Câmara como uma tevê pública, como muita gente vê. Eu a vejo como uma tevê institucional. Isso me orgulha muito. Eu trabalho para uma instituição, talvez a mais importante da República, que é o Poder Legislativo. Não me diminui nada dizer que trabalho para uma tevê institucional em vez de uma tevê pública. A gente pode até falar que a TV Câmara faz parte de uma coisa que se poderia chamar de campo público onde estariam as tevês universitárias e as tevês educativas etc. Mas eu a entendo como uma tevê institucional. Então, é uma tevê que dá transparência aos atos praticados no âmbito da Câmara dos Deputados. Inclusive o confronto de opiniões, pois uma das funções aqui é ser fórum de discussões e dar curso às investigações e à fiscalização dos demais poderes.
\end{abstract}

\begin{abstract}
Acho que ela é institucional, à medida que você dedica espaço ao Plenário. Tem dia que você passa doze horas de Plenário. Só uma tevê institucional passa doze horas de Plenário, porque o Plenário não é uma atividade em que o formato seja adequado à televisão, entendeu? Nós estamos na sociedade do espetáculo, em que todas as solenidades públicas, a troca da guarda da rainha, os shows de rock, as missas, tudo hoje está adequado à televisão. O formato da cena pública hoje é para ser uma cena televisada. E o nosso Plenário não é uma peça televisada, ele é péssimo para a televisão. É difícil você ver, porque tem discurso muito longo, as pessoas falam demais, falam alto, falam errado, quem não é um conhecedor da atividade do Plenário tem uma dificuldade de identificar as coisas ali e discernir o que está acontecendo. Então, se você dá dize horas por dia de Plenário, só pode ser uma tevê institucional, entendeu? Nenhuma outra tevê daria doze horas de Plenário. Nem pública, nem privada, nem estatal, nem nada. Só mesmo uma tevê da instituição.
\end{abstract}

Um dos profissionais ressalta que a comunicação institucional precisa ser feita pelas mídias legislativas, pois elas representam a instituição, atuam como porta-vozes oficiais do órgão.

\begin{abstract}
A questão institucional vez ou outra precisa fazer parte disso. Mas eu acho normal. A igreja católica tem a Rede Vida, a emissora de televisão dela. Vamos fazer uma comparação bem direta com a Câmara. Quando ela é atacada em alguma coisa, nada mais legítimo que ela se defender por meio daquela rede. Eu acho normal. Ou que defenda os pontos de vista dela nessa rede também. Que use a rede para amplificar os pontos de vista dela. Para prestar contas, no caso da Rede Vida, à massa de pessoas que têm aquela devoção religiosa e que precisa disso. Ou para as pessoas que trabalham na grande instituição, porque a lgreja Católica tem toda uma ramificação, toda uma estrutura pelo país para se sustentar, então ela precisa da comunicação, é um negócio valiosíssimo esse veículo de comunicação para ela fazer essa máquina que a sustenta funcionar corretamente. No caso da Câmara acho que é a mesma coisa: há milhões de coisas institucionais que a gente tem que destacar, tem que informar. Não tenho pudor disso. É diferente de você usar a TV Câmara para divulgar, para fazer a divulgação muito intensiva das atividades de alguém que, por exemplo, naquele momento ocupa a presidência da Câmara. Acho que a presidência da Câmara tem naturalmente uma presença muito forte na TV Câmara e na rádio e no jornal porque o presidente é uma figura que, digamos assim, "está em todas". Em todas as questões ele está participando, é natural que ele apareça muito, que o nome dele seja citado o tempo inteiro. Mas isso faz parte de uma circunstância noticiosa.
\end{abstract}

\title{
Sistema híbrido de comunicação pública
}

As condições específicas de trabalho dos profissionais de comunicação da Câmara num sistema híbrido, que mistura práticas e critérios clássicos do jornalismo com atividades e conteúdos de comunicação institucional, ultrapassam as fronteiras da instituição para atuar na formação e na instrução dos cidadãos. Estrategicamente, o conhecimento dos públicos com os quais se relaciona é essencial para a sobrevivência de qualquer instituição. 0 estabelecimento de canais de comunicação com esses públicos é, portanto, inevitável. Mas a comunicação institucional também é essencial para divulgação do conhecimento sobre a instituição e para que o cidadão tenha canais de acesso aos dirigentes políticos, no caso da Câmara.

Em uma instituição do estado, a comunicação institucional assume um caráter ainda mais público e amplo, pois o interesse primeiro da instituição éa continuidade da prestação do serviço ao cidadão. Segundo Pierre Zémor (1995), uma das finalidades 
principais da comunicação pública, isto é, daquela feita pelas instituições públicas, é exatamente o esclarecimento da população sobre o funcionamento institucional, os valores e as funções das diferentes instituições e sobre os debates dos projetos de mudança institucional e de políticas públicas.

Na esteira de tais reflexões, seguimos a ideia de que a informação política é essencial para a democracia e o exercício da cidadania. No caso específico de sistemas públicos de comunicação, como afirma Zémor, as mensagens são emitidas, recebidas, tratadas pelas instituições públicas "em nome do povo", da mesma forma como são votadas as leis ou pronunciados os julgamentos. Logo, essa comunicação se situa necessariamente no espaço público, sob o olhar do cidadão, e as informações que divulga são de domínio público, pois assegurar o interesse geral implica transparência (Zémor, 1995).

0 papel da comunicação nessa perspectiva é estratégico, uma vez que o processo político se apoia, decisivamente, na atividade comunicativa colocada em prática na sociedade. Um dos fundadores e principais pesquisadores dessa vertente teórica é Jürgen Habermas. Segundo ele, na teoria deliberativa, "tudo gira em torno das condições de comunicação e dos procedimentos que outorgam à formação institucionalizada da opinião e da vontade políticas sua força legitimadora" (Zémor, 1995, p. 45). A comunicação necessária à deliberação pública inclui os atores periféricos ao sistema político, tais como grupos marginalizados e excluídos do sistema representativo formal. A autonomia desses grupos no debate é condição para a legitimidade da esfera pública. A democratização, para Habermas (1992, p. 87) significa o crescimento e a consolidação de esferas públicas autônomas entre os cidadãos.

Apesar de a criação de canais cada vez mais sofisticados de participação ser uma tarefa que muitas instituições políticas têm desenvolvido, é importante lembrar, contudo, que tais ferramentas não eliminam os obstáculos tradicionais à participação política: falta de informação, apatia e desconexão entre cidadão e representante (Maia, 2011, p.68). E tampouco eliminam as assimetrias de poder que permeiam as relações dos cidadãos com os órgãos da administração pública, "uma vez que estamos submissos ao poder público (...), lembrados de nossos deveres e incitados à aprendizagem de meandros da lei e das sutilezas de sua aplicação" (Petitat, 2001, p. 371).

A própria Constituição de 1988 já inclui o sistema público de comunicação, em oposição clara aos sistemas privado e estatal de mídia ${ }^{6}$, sem, contudo, definir exatamente que tipo de veículo compõe cada um dos sistemas. Desse modo, ainda que haja um certo consenso sobre a mídia comercial (privada), a separação constitucional entre os sistemas público e estatal provoca muitas controvérsias entre profissionais e estudiosos.

Entre as divergências, está a inclusão do jornalismo praticado em órgãos estatais, sejam eles do Executivo, do Judiciário ou do Legislativo, no critério de "públicas". A divisão prevista na Constituição aponta para a conclusão de que o sistema estatal é aquele gerido pelo governo, enquanto o sistema público seria gerido por instituições da sociedade civil, sem a lógica comercial dos veículos privados, contudo. Tal conceito é adotado no Glossário de comunicação pública(Duarte; Veras, 2006. p. 64) com a definição de diferentes tipos de jornalismo público (de patrocínio, de campanhas, institucional, promocional, do terceiro setor) produzidos por organizações não-governamentais. Contudo, até mesmo os estudiosos do assunto obrigam-se a incluir no ramo da comunicação pública as emissoras de televisão dos estados (educativas), legislativas e universitárias, além das comunitárias e dos veículos das instituições não-governamentais e fundações (Silva, 2006, p. 57).

6 A Constituição Federal define em seu artigo 223 que compete ao Poder Executivo outorgar e renovar concessão, permissão e autorização para o serviço de radiodifusão sonora e de sons e imagens, observado o princípio da complementaridade dos sistemas privado, público e estatal. 
Na visão de Zémor (2009), o comunicador público se comunicará mais adequadamente com o exterior quanto mais eficiente for a comunicação interna na instituição pública em que atua: "Para brilhar fora é preciso limpar por dentro. É preciso transparência na maneira como funcionam as instituições". Ele observa que, se houver possibilidade de a instituição pública abrir um canal direto de informação ao cidadão, os jornalistas dos veículos de comunicação poderão exercer seu poder de crítica em relação àquela instituição.

Para o autor francês, os comunicadores públicos mais eficientes são os profissionais oriundos da própria instituição pública e que conhecem bem a Casa, pois a comunicação pública não tem a mesma lógica das empresas. "É preciso averiguar quais são as preocupações dos cidadãos e saber que respostas estão adequadas. 0 risco é haver um divórcio entre a comunicação da sociedade e a das instituições públicas". Já a comunicação de gabinetes, diz Zémor, tem conteúdos mais políticos. "0 debate público não apontará a decisão, apenas fará a concertação. A comunicação é um negócio de especialistas apenas para a sua implementação prática". Nesse sentido, Zémor defende o estabelecimento de uma "relação de confiança perene" entre instituição pública e o cidadão, escutando-o e informando-o sobre o que é ou não possível fazer na administração pública, num diálogo adulto com a população. "A prática participativa aumenta a democracia", afirma.

\section{A comunicação institucional e a esfera parlamentar}

Cabe ressaltar ainda as tensões entre a esfera burocrático-informacional e os gabinetes parlamentares, com seus interesses divergentes e suas visões particulares sobre o papel dos veículos de comunicação e dos canais de interatividade. Se para os profissionais de comunicação a função do sistema é de aproximação e de diálogo com a sociedade, na perspectiva defendida por Habermas e Zémor, para os gabinetes a principal função é percebida como instrumental. Em outras palavras, para os parlamentares a comunicação institucional deve ser ferramenta a serviço da promoção política e da conexão eleitoral com suas bases.

Além disso, o foco dos gabinetes é a divulgação promocional, capaz de otimizar o capital político da publicidade do mandato, com vistas à reeleição. Quando se trata da esfera da deliberação pública, da participação do cidadão e dos segmentos organizados da sociedade civil, a tendência dominante dos gabinetes é de fechamento. Demonstração dessa tendência é que já houve manifestação ostensiva de gabinetes em não receber as manifestações da sociedade coletadas pelo DisqueCâmara (0800) e pelo Fale Conosco (e-mail institucional). Levantamento realizado pelo setor de Relações Públicas em 2009 mostrou que 97\% dos gabinetes deletam as mensagens da população sem ler. Dezenas de gabinetes, secretários de comissão e diretores de órgãos administrativos reclamam com frequência aos gestores do Disque-Câmara porque não gostariam de receber as mensagens da população. Diante da informação de que se trata de uma determinação da diretoriageral da instituição para que todos os dados sejam enviados regularmente, desistem da reclamação, mas manifestam explicitamente o descontentamento. A alegação mais comum é de que as mensagens não são passíveis de serem respondidas com objetividade e que muitas não são compreensíveis, não são claras ou são redundantes e desconexas.

Pesquisa realizada com os gestores de informação dos gabinetes em 2011 (Santana, 2011) mostra que os gabinetes alegam falta de infraestrutura e de pessoal qualificado para fazer a triagem e o atendimento das mensagens recebidas pelo DisqueCâmara. A mesma pesquisa concluiu que não há uma política comum para os gabinetes em termos de como lidar com a participação popular. Cada gabinete tem autonomia para decidir como lhe convém e nem sempre a decisão é do próprio deputado, mas do secretário parlamentar ou outro funcionário responsável pela caixa de e-mail institucional oferecida pela Câmara. Na prática, "raramente uma mensagem é mostrada ao deputado" (Santana, 2011, p. 52). Além disso, mais de 
30\% dos gabinetes sequer têm conhecimento das atribuições do Disque-Câmara. A mesma pesquisa mostra que dos 513 gabinetes, 188 não conhecem o serviço e nem sabem quais são as suas atribuições.

Esses dados reiteram o pressuposto defendido pelo texto acerca dos conflitos e das tensões institucionais e políticas, além das dissonâncias de valores entre a esfera burocrática e a estrutura política da instituição. A primeira tenta se pautar pelo planejamento estratégico e a ação racional, elementos típicos da ética da responsabilidade (objetiva), enquanto a segunda opera com os critérios da ética da convicção (subjetiva). Há uma assimetria entre o modelo de gestão institucional e os padrões de administração dos gabinetes, o que faz com que essas estruturas "pareçam pertencer a duas instituições diferentes e, dessa forma, como poderia a Câmara ser eficiente mantendo unidades tão assimétricas?" (Santana, 2011, p. 64).

\section{CONSIDERAÇÕES FINAIS}

0 maior desafio da instituição para os próximos anos, em termos de comunicação institucional é completar o diálogo com a sociedade, conforme propõem Zémor e Habermas, o que significa produzir resultados no processo legislativo. Para que a participação resulte em eficácia política, seria necessário que a instituição construísse condições internas, priorizando um arranjo institucional respaldado por um planejamento estratégico eficiente, incluindo um sistema de avaliação permanente do sistema de informação e dos canais de interatividade. Por outro lado, apesar das limitações, é inegável que a comunicação institucional e a interatividade tendem a ser cada vez mais valorizadas politicamente, à medida que passarem a permear as principais formas de manifestação da política. A participação está diretamente associada à visibilidade e à transparência, elementos resultantes dos consensos e acordos tecidos no âmbito das negociações políticas.

Entre outros problemas para o aproveitamento da participação do cidadão, podem ser citados a falta de estruturação mínima dos gabinetes para sistematização da participação, falta de visão dos parlamentares sobre as oportunidades de conexão eleitoral criadas por esses instrumentos (ou mesmo baixa preocupação com o bem coletivo ainda que sem conexão eleitoral) e falta de compreensão dos processos de participação pelos agentes políticos, especialmente aqueles realizados por meio das ferramentas digitais. Alguns parlamentares, entretanto, começam a fazer um uso mais intensivo desses canais de participação para mobilização dos cidadãos. Resta despertar o interesse dos demais agentes políticos para a importância desse fórum de debates.

Contudo, cabe ressaltar que nem todos os parlamentares estão dispostos a negociar sua forma de exercer seu mandato e de estabelecer relacionamento com suas bases eleitorais e muito menos aderir a um projeto focado no interesse da instituição. A cultura parlamentar brasileira nem sempre está ancorada nos princípios da democracia deliberativa ou participativa. 0 projeto de comunicação Câmara dos Deputados pode até ser aceito pelos representantes da sociedade civil, mas nem sempre encontra ressonância nos gabinetes. Apesar da renovação na cultura parlamentar, ainda existem deputados que exercem 0 mandato sobre os pilares da política tradicional (localismo, personalismo e autoritarismo) sem abertura para um processo contínuo de relação/debate com a sociedade. Além disso, existe o contraponto da cultura política do eleitor, que ainda vota nesse tipo de representante e espera um comportamento parlamentar à moda antiga. A eficácia de um projeto de comunicação institucional não depende apenas da decisão da Câmara no que se refere à oferta e à gestão de canais de interatividade. Sem a adesão dos deputados e dos eleitores ao projeto institucional os efeitos serão restritos ao âmbito da microfísica dos espaços administrativos e burocráticos da Câmara, sem consequências em termos de deliberação pública e de participação política. 


\section{REFERÊNCIAS}

BERNARDES, Cristiane Brum. Política, institucional ou pública? Uma reflexão sobre a mídia legislativa da Câmara dos Deputados. 2010. Tese (Doutorado em Ciência Política) - Instituto de Estudos Sociais e Políticos (lesp) da Universidade Estadual do Rio de Janeiro (Uerj) e Centro de Formação, Treinamento e Aperfeiçoamento (Cefor) da Câmara dos Deputados, Brasília.

BLUMLER, Jay G.; GUREVITCH, Michael. Journalists' orientations to political institutions: the case of parliamentary broadcasting. In: GOLDING, Peter; MURDOCK, Graham; SCHLESINGER, Philop. Communicating politics. New York: Holmes \& Meier; Leicester University Press, 1986. p. 67-92.

BRASIL. Resolução da Câmara dos Deputados nº 20, de 1971. Seção IV, Da Assessoria de Divulgação e Relações Públicas. Brasília, Câmara dos Deputados, 1971.

DUARTE, Jorge; VERAS, Luciana (Org.). Glossário de comunicação pública. Brasília: Casa das Musas, 2006.

GOMES, Wilson. Transformações da política na era da comunicação de massa. São Paulo: Paulus, 2004.

HABERMAS, Jürgen. Três modelos normativos de democracia. Lua Nova, São Paulo, n. 36, p. 39-53, 1995.

MAIA, Rousiley Celi Moreira. Internet e esfera civil: Limites e alcances da ticipação política. In: MAIA, Rousiley Celi Moreira; GOMES, Wilson; MARQUES, Francisco Paulo. (Org.). Internet e participação política no Brasil. Porto Alegre: Sulina, 2011. p. 47-91.

MALAVAZI, Aemir. Manual de redação da Secom. Brasília: Câmara dos Deputados, 2004.

PETITAT, André. Educação difusa e relação social. Educação \& Realidade, Porto Alegre, Universidade Federal do Rio Grande do Sul, v. 36, n. 2, p. 365-376, maio/ago. 2011.

QUEIROZ, Dulce. Jornalismo institucional nas TVs legislativas: os casos do Brasil e do México. 2007. Dissertação (Mestrado em Comunicação Social) - Programa de Pós-Graduação da Faculdade de Comunicação Social, Universidade de Brasília (UnB), Brasília.

SANTANA, Dinajara Daniel Figueiredo. Uso das informações da Central de Comunicação Interativa da Câmara dos Deputados pelos gabinetes parlamentares. Monografia (Especialização) - Curso de Gestão Pública Legislativa. Brasília: Câmara dos Deputados - Centro de Formação, Treinamento e Aperfeiçoamento (Cefor), 2011.

SILVA, Heloiza Dias da. A comunicação no Poder Executivo Federal: o Ministério da Agricultura Pecuária e Abastecimento. São Paulo: Embrapa, 2006.

TORQUATO, Gaudêncio. Comunicação empresarial/comunicação institucional:'conceitos, estratégias, sistemas, estruturas, planejamento e técnicas. São Paulo: Summus, 1986.

ZÉMOR, Pierre. La communication publique. Paris: PUF, 1995.

Artigo recebido em 20.09.2014 e aprovado em 01.06.2015. 